\title{
Fifteen years of losartan: what have we learned about losartan that can benefit chronic kidney disease patients?
}

\author{
Elizabeth Ripley \\ Ari Hirsch \\ Division of Nephrology, Virginia \\ Commonwealth University, Richmond, \\ Virginia, USA
}

This article was published in the following Dove Press journal: International Journal of Nephrology and Renovascular Disease 24 June 2010 Number of times this article has been viewed

REVIEW

\begin{abstract}
Losartan, the first AT1 receptor blocker (ARB), was FDA approved 15 years ago. During those years, researchers and clinicians have developed a growing base of knowledge on the benefits of losartan, particularly for hypertension and renal disease. These benefits include decreasing proteinuria, slowing the progression of diabetic nephropathy, controlling hypertension, and decreasing stroke risk in patients with left ventricular hypertrophy. Although many of the benefits of losartan represent a class effect for ARBs, losartan has pharmacokinetic and pharmacodynamic characteristics and effects that are unique and are not a class effect. For example, a shorter duration of action is seen with this first ARB compared with other more recently approved ARBs. Losartan also has a uricosuric effect not seen in other ARBs and attenuates platelet aggregation, which is not seen or is seen to a lesser extent with the other ARBs. This review presents the physiological effects of losartan on the kidney and discusses relevant clinical outcomes.
\end{abstract}

Keywords: losartan, chronic kidney disease

Losartan was first Food and Drug Administration (FDA) approved in 1995 as an antihypertensive and is scheduled for generic release in April 2010. ${ }^{1}$ During the past 15 years, there has been great progress in understanding the effects of angiotensin II (AII) in the kidney and the benefits of blockade of AII at the AT1 receptor. Although losartan is now one of many angiotensin receptor blockers (ARBs), it was the first clinically used and has significantly contributed to both the physiologic understanding of AII and the clinical benefit of AII blockade. This review will present the renal effects of AT1 receptor blockade and the clinical benefits, which have been seen with losartan. It is understood that many of the effects of losartan are a class effect; however, there are 2 effects that are novel to losartan: uricosuria and effects on thrombosis. Many articles have been written about losartan; in fact, a Medline search for "losartan" returned 6,396 articles, "losartan and the kidney" 1,419, "losartan and hypertension" 2,596, and "losartan and chronic kidney disease" 262. It would be impossible to detail results of all of these. Instead an overview of the benefits of losartan is presented. Because vascular disease is a major morbidity and mortality for kidney disease patients, important outcome findings with congestive heart failure and stroke prevention are also included. Although many would consider losartan the weakest of the class, it has no doubt lead to impressive findings and important outcomes.

Correspondence: Elizabeth Ripley Division of Nephrology PO Box 980160 , Richmond,VA 23298, USA

Tel $+1804-687-3062$

Fax +1804-687-3062

Email eripley@mcvh-vcu.edu

\section{Pharmacokinetics and FDA approval}

Losartan is a nonpeptide molecule, which is a competitive antagonist with selective binding to AT1 receptors. Losartan has an oral bioavailability of $33 \%$ and has significant first-pass 
metabolism using the cytochrome P450 system. Specifically, the cytochrome P450 enzymes, CYP2C9 and CYP3A4, are involved with the biotransformation to the active metabolites that are 10-40 times more potent by weight than the parent molecule losartan. The metabolites appear to be a reversible, noncompetitive inhibitor of the AT1 receptor. Elimination of losartan is approximately $40 \%$ in urine and $60 \%$ in feces. Losartan and its metabolites are highly protein bound, mainly to albumin, but other plasma proteins bind them leaving only $1.3 \%$ and $0.2 \%$ free, respectively. The half-life of losartan is 2 hours with the terminal half-life of the metabolites being longer at 6-9 hours. ${ }^{2}$ When dosed twice a day, its blood pressure lowering is equivalent to other ARBs given once a day.

Losartan has FDA approval for the treatment of hypertension either alone or in combination with other antihypertensives, including diuretics. In patients with both hypertension and left ventricular hypertrophy (LVH), it is indicated to reduce the risk of stroke (although the benefit in black patients was not seen in the supporting trial). The third indication is for diabetic nephropathy in patients with type 2 diabetes with an elevated serum creatinine and proteinuria in order to reduce the occurrence of doubling of serum creatinine or end-stage renal disease. ${ }^{2}$ Although these are the FDA-approved indications for the clinical use of losartan, as discussed below, the benefit of losartan has been tested in multiple other settings.

\section{Effects of losartan on the kidney}

AT1 plays a significant role in the hemodynamic, electrolyte, and fluid balance regulation of the kidneys. Xu, Mao, Liu, WU and Xu have previously carefully outlined the intrarenal renin-angiotensin-aldosterone system (RAS). ${ }^{3}$ In order to understand the multiple effects of losartan, it is critical to understand the local effects of the RAS system, particularly the effects of AT1 receptors. The concentration of AII is about 1,000 times higher in the kidney than in the circulation. All the key elements of the RAS system have been demonstrated within various portions of the kidney, and its action have shown both paracrine and autocrine regulation. The AT1 receptor has been detected in almost all parts of the nephron. ${ }^{4}$ The AII activation of the AT1 receptor leads to upregulation of angiotensinogen, rennin, and angiotensin-converting enzyme (ACE). Thus, losartan by blocking the AT1 receptor leads to decreased intrarenal AII by blocking this upregulation. ${ }^{5}$ Table 1 shows the effects of losartan on the kidney.

Blocking AT1 receptors in the kidney have multiple effects that can be beneficial. For instance, AII causes contraction of mesangial cells leading to a decrease in glomerular filtration rate (GFR), which can be blocked by losartan. However, the overall effect of losartan on GFR can be variable, depending on whether the blood pressure remains in the renal autoregulatory range. If the blood pressure is within this range, losartan is associated with an increase in GFR. ${ }^{6}$ However, with low blood pressure, it may be associated with decreased, increased, or unchanged GFR. ${ }^{7}$

In pathologic states, AT1 blockade improves the impaired autoregulation induced by chronic abnormal activation of RAS. ${ }^{8}$ AT1 receptor blockade has experimentally been shown to decrease renal fibrosis as AII promotes deposition of extracellular matrix in the mesangium. AT1 activation also increased TGF- $\beta 1$ that activates fibroblasts and increases their transformation to myoblasts, which in turn leads to fibrosis. ${ }^{9} 10$ Losartan may also be able to decrease inflammation by decreasing leukocyte proliferation and blocking upregulation of adhesion molecules. ${ }^{11}$ Because of these renal effects, it is not surprising that outcome studies have shown a benefit to blocking AT1 receptors with losartan.

\section{Losartan and uric acid}

A unique effect of losartan (compared to other AT1 receptor blockers) is to reduce proximal tubular reabsorption of uric acid leading to increased uric acid excretion and decreased serum uric acid concentrations. ${ }^{12}$ The magnitude of changes in uric acid levels has been variable in studies where losar$\tan$ is used as an antihypertensive. ${ }^{13-17}$ These decreases in

Table I Renal effects of blocking ATI receptors

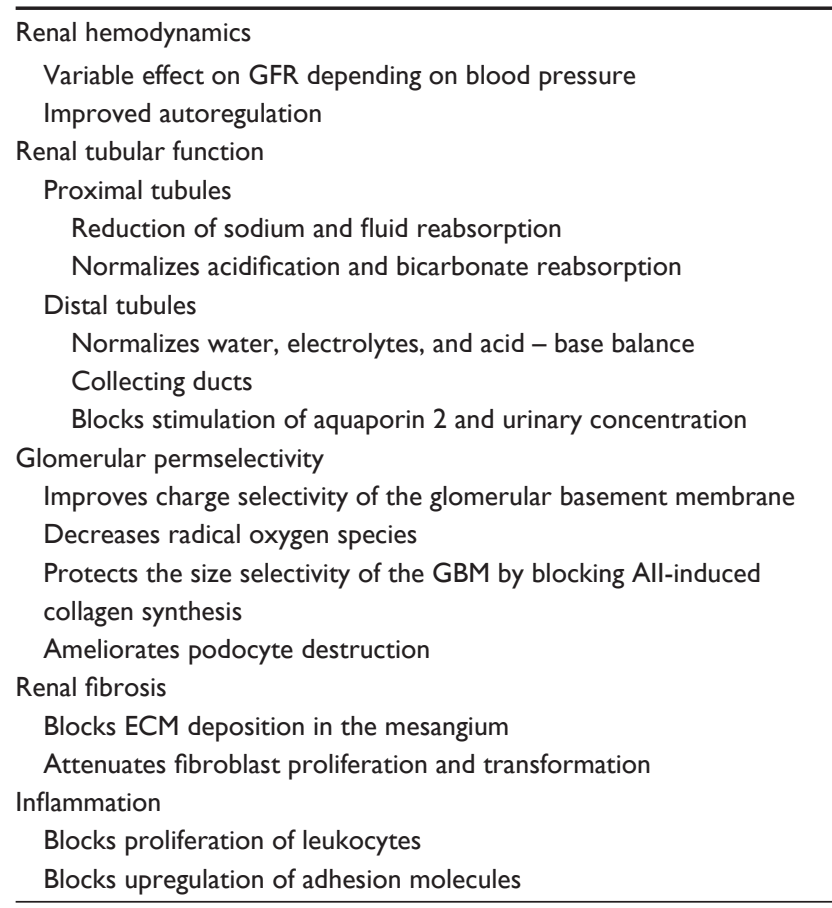

Abbreviations: ECM, extracellular matrix; GBM, glomerular basement membrane; GFR, glomerular filtration rate; All, angiotensin II. 
uric acid levels have also been seen in patients with renal insufficiency. Interestingly, patients with end-stage renal disease on hemodialysis also had a decrease in uric acid levels even though urinary losses could not explain this. ${ }^{18}$ The clinical implication of decreasing uric acid levels as a mechanism to decrease cardiovascular risk is unknown.

Hyperuricemia is a significant post-transplant complication in patients treated with cyclosporine. Kamper and Nielsen showed that losartan treatment in hypertensive post-transplant patients decreased fractional excretion of uric acid by $17 \%$ and decreased plasma uric acid by $8 \%{ }^{19}$ In a recent study by Zhu et $\mathrm{al}^{20} 66$ Han Chinese postrenal transplant patients were enrolled at least 3 months post transplant and with stable renal function. Thirty-four were treated for 6 months with losartan $50 \mathrm{mg} / \mathrm{d}$ and 32 served as controls. Uric acid levels significantly decreased, particularly in those with hyperuricemia. It must be noted that 9 patients in the treatment group and 5 in the control group withdrew due to acute renal insufficiency, anemia, acute rejection, or poor compliance. A second finding of this study was that hematocrit levels decreased in the losartan-treated patients, particularly in those with post-transplant erythrocytosis.

\section{Losartan and antiplatelet action}

Losartan exerts an antiplatelet action by blockade of thromboxane A2 (TxA2) receptors. ${ }^{21}$ In the animal model using the stroke-prone spontaneously hypertensive rat, losartan has been shown to reduce platelet activation and aggregation while causing vasodilation. ${ }^{22,23}$ In this model, this was shown not to be a class effect of ARBs as candesartan and valsartan had no effect on platelet activation. ${ }^{23}$ In humans, losartan and irbesartan have demonstrated this effect, while at higher doses, valsartan and telmisartan have inhibited platelet aggregation. ${ }^{24-26}$ Candesartan does not appear to influence platelet aggregation. ${ }^{27}$ In the usual therapeutic dosing range, losartan has been shown to be effective. This effect is not seen with ACE inhibitors.

\section{Losartan and proteinuria}

Reduction of proteinuria is associated with stabilization of renal disease or slowing of its progression. This has been seen in both diabetic and nondiabetic nephropathy and is both dependent and independent of blood pressure lowering. ${ }^{28}$ Losartan has also been shown to decrease proteinuria in nondiabetic nephropathies. For instance, losartan at $50 \mathrm{mg} / \mathrm{d}$ significantly decreased proteinuria in a small group of patients with biopsyproven AA amyloidosis treated for 12 months compared with control patients with similar mean arterial blood pressure. ${ }^{29}$
In a larger trial of hypertensive patients, losartan significantly decreased proteinuria more than amlodipine in patients with higher and lower baseline levels of proteinuria. ${ }^{30}$ An additional example is a reduction of proteinuria in normotensive patients with focal segmental glomerulosclerosis. ${ }^{31}$

\section{Losartan and renal protection}

Blood pressure reduction is associated with renal protection and slowing of progression of chronic kidney disease (CKD). Losartan lowers blood pressure alone and in combination with other antihypertensives. ${ }^{32,33}$ Blood pressure reduction is only part of the benefit of RAS blockade for renal protection. ARBs have been shown to provide antihypertensive and renoprotective effects similar to those achieved with ACE inhibitors. The Renalprotection of Optimal Antiproteinuric Doses (ROAD) trial showed that titration to maximal antiproteinuric effect of benazepril or losartan beyond usual antihypertensive ranges did not show increased blood pressure reduction but was associated with a significant reduction in the risk of doubling of the serum creatinine concentration by $49 \%$ and $50 \%$, respectively, at 3.7 years. This was associated with a decrease in end-stage renal disease (ESRD) risk by $47 \%$ with both drugs. ${ }^{34}$

There has been 1 large trial to show the outcome benefit of losartan in type 2 diabetes patients. In this trial, 1,513 individuals with a mean creatinine of $1.9 \mathrm{mg} / \mathrm{dL}$ were enrolled in the The Reduction of End Points in Type 2 Diabetes with the Angiotensin II Antagonist Losartan (RENAAL) study. During a follow-up of 3.4 years, treatment with losartan reduced the incidence of a doubling of the serum creatinine concentration (risk reduction, $25 \% ; P=0.006$ ) and ESRD (risk reduction, $28 \% ; P=0.002$ ). This protection was larger than what would be expected with blood pressure reduction alone and that these benefits exceeded those attributable to measured reductions in blood pressure. ${ }^{35}$ The most significant risk factor for progression was the degree of proteinuria at baseline and at 6 months. ${ }^{36-38}$ At 6 months, losartan reduced proteinuria by $28 \%$ while the placebo was associated with a $4 \%$ increase in proteinuria. ${ }^{36}$

The combination of ACE inhibitor with ARB has been shown to have a significant benefit in reduction of proteinuria. ${ }^{39,40}$ However, these and other studies have used submaximal dosing of each drug leaving questions as to whether the addition of an ACE inhibitor to doses of an $\mathrm{ARB}$, which is at maximal antiproteinuric effect (or vice versa) would be of added benefit. Unfortunately, there is insufficient evidence to show that combination treatment slows the progression of renal disease. Initially, the combination treatment of angiotensin-II receptor blocker and ACE 
inhibitor in nondiabetic renal disease (COOPERATE) study was thought to show this benefit; however, due to significant questions regarding this study, it was later retracted. ${ }^{41}$

The first effective, oral, direct renin inhibitor, aliskiren, has been evaluated in combination with the first ARB. A trial of aliskerin plus losartan in type 2 diabetic nephropathy showed a greater significant reduction of $20 \%$ in proteinuria compared with losartan alone. The outcome benefit on slowing the progression of renal disease has not yet been shown. ${ }^{42}$

\section{Losartan and heart failure outcome trials}

Blockade of the RAS system has been shown to improve survival and hospitalizations in heart failure patients being treated with ACE inhibitors. These benefits of treating with losartan have also been evaluated. The first trial, Evaluation of Losartan in the Elderly (ELITE) compared treatment of NYHA class II-IV heart failure patients (age 65 or older) treated with captopril (up to $50 \mathrm{mg}, 3$ times a day) and losar$\tan$ (up to $50 \mathrm{mg}$ a day) treated for 47 weeks. The primary end point was a worsening renal function. There were no significant changes in renal function. It is important to note that the event rate was lower than anticipated, and therefore, the study may not have been powered to show a significant difference. As a secondary end point, mortality was decreased $46 \%$ in the losartan-treated patients. ${ }^{43}$ To show superiority of losartan, a second trial ELITE II enrolled 3,152 patients (age 60 or older) with NYHA class II-IV heart failure and a left ventricular ejection fraction of $40 \%$ or less. Patients were treated with either losartan $50 \mathrm{mg}$ a day or captopril $50 \mathrm{mg} 3$ times a day. There were no statistical differences between the 2 treatment arms regarding the primary end points, including sudden death and the composite of mortality and hospitalizations. Losartan was better tolerated than captopril with fewer patients discontinuing prematurely owing to adverse events (not counting death). ${ }^{44}$

These 2 studies were conducted with losartan $50 \mathrm{mg}$ a day. Higher doses of losartan are associated with further decrease in blood pressure, and with increases up to $150 \mathrm{mg}$ of losartan, there is increasing renin levels and circulating AII. ${ }^{45}$ The Effects of high-dose versus low-dose losartan on clinical outcomes in patients with heart failure (HEAAL study) was a randomized, double-blind trial of losartan of $150 \mathrm{mg}$ compared with losartan of $50 \mathrm{mg}$ in patients with heart failure, who were intolerant of ACE inhibitor therapy for a median follow-up of 4.7 years. The primary end point was death or admission for heart failure. With an intention to treat analysis, there was no difference in deaths, but there was a significant decrease in hospitalizations for heart failure with fewer hospitalizations with the higher dose. Renal impairment, hypotension, and hyperkalemia were also higher in the higher dose group, but there was not an increase in discontinuation rate in this group. ${ }^{46}$

\section{Losartan intervention for endpoint reduction trial as a look at losartan benefits}

The Losartan Intervention for Endpoint Reduction (LIFE) trial was a double-blind study of 9,193 hypertensive patients between the ages of 55 and 80 , who were at high risk. The entry criteria included hypertension and LVH (determined by ECG). Participants were randomly assigned to either losartan or atenolol. Doses were increased and hydrochlorothiazide or other medications were added to obtain a target blood pressure of less than 140/90 mmHg. Both medications were started at $50 \mathrm{mg}$ and titrated to $100 \mathrm{mg}$ as needed. The primary end points were occurrence of cardiovascular death, myocardial infarction, or stroke, and the composite end point was any of these events. Losartan was associated with a significantly decreased incidence of the primary composite end point. This was primarily due to a decrease in fatal and nonfatal stroke. Blood pressure control was similar in the 2 groups. This stroke benefit was not seen in African Americans. ${ }^{47}$

Substudies of this outcome trial have provided a number of additional benefits of losartan therapy in this population. Findings show a benefit of losartan over atenolol in surrogate markers, as well as in clinical outcomes. For example, losartantreated individuals had significant $\mathrm{LVH}$ regression ${ }^{48,49}$ and decrease in left atrial size ${ }^{50,51}$ and decreased BNP. ${ }^{52,53}$ They also had decreased platelet aggregation, decreased serum uric acid, ${ }^{54}$ improved insulin sensitivity, ${ }^{55}$ attenuated decline in HDL, ${ }^{56}$ and decreased proteinuria. ${ }^{57}$ All of these would be significant surrogate markers for improved cardiovascular risk. Clinically significant findings were decreased incidence of atrial fibrillation $^{58}$ and new onset diabetes. ${ }^{47,59}$ These may help explain the positive outcome of the LIFE trial and may prove useful to patients with chronic kidney disease after further studies. ${ }^{58}$

\section{The economic impact of losartan}

Several studies have looked at the economic impact of treating patients with type 2 diabetes with losartan using the RENAAL trial for analysis. A cost benefit was seen after 2-2.5 years, and at 4 years of follow-up, the cost savings by averting days with ESRD was $\$ 5,300 /$ patient $(95 \%$ CI, US $\$ 950-9,600){ }^{60}$ A Mexican cost assessment using the RENAAL trial showed that treatment with losartan led to greater life expectancy and 
lower cost. ${ }^{61}$ Using the LIFE trial, a Netherland's study noted that the medication costs for atenolol was \$64 lower than for losartan, but the net cost per life year gained was only $\$ 1,083$, well under the cost that is usually considered worth utilizing a treatment. ${ }^{62}$ Losartan has been a preferred drug on most managed care medication lists, and now that it will soon be generic, the cost benefit will increase.

\section{Conclusion}

Over the past 15 years, there has been a wide variety of studies conducted with losartan. It has shown benefit in controlling hypertension, decreasing proteinuria, slowing the progression of type 2 diabetic nephropathy, and decreasing the risk of stroke in certain populations. In addition, favorable surrogate markers such as decreased platelet aggregation, decreased uric acid, decreased proteinuria, and regression of LVH have also been documented. For a first in class medication, which is touted as being a weaker angiotensin receptor blocker, it has shown remarkable outcomes. Although, pharmacokinetic differences, particularly the shorter half-life, should be kept in mind, this drug should remain an active part of our armamentarium.

\section{Disclosures}

Dr Ripley has been a consultant and speaker for AstraZeneca.

\section{References}

1. Going Generic. Available at http://www.cozaar.com/losartan_potassium/ hyzaar/hcp/going_generic/?WT.svl=5 Accessed Mar 15, 2010.

2. Cozaar_pi.pdf(application/pdf Object). Available at http://www.merck. com/product/usa/pi_circulars/c/cozaar/cozaar_pi.pdf Accessed Mar 15, 2010.

3. Xu H, Lv M, Tian X. A review on hemisynthesis, biosynthesis, biological activities, mode of action, and structure-activity relationship of podophyllotoxins: 2003-2007. Curr Med Chem. 2009;16:327-349.

4. Tufro-McReddie A, Harrison JK, Everett AD, Gomez RA. Ontogeny of type 1 angiotensin II receptor gene expression in the rat. J Clin Invest. 1993; 91:530-537.

5. Zhuo JL, Imig JD, Hammond TG, Orengo S, Benes E, Navar LG. Ang II accumulation in rat renal endosomes during ang II-induced hypertension: Role of AT(1) receptor. Hypertension. 2002;39:116-121.

6. Cervenka L, Navar LG. Renal responses of the nonclipped kidney of two-kidney/one-clip goldblatt hypertensive rats to type 1 angiotensin II receptor blockade with candesartan. JAm Soc Nephrol. 1999;10 Suppl 11: S197-S201.

7. Bidani AK, Griffin KA. Long-term renal consequences of hypertension for normal and diseased kidneys. Curr Opin Nephrol Hypertens. 2002;11:73-80.

8. Inscho EW, Imig JD, Deichmann PC, Cook AK. Candesartan cilexetil protects against loss of autoregulatory efficiency in angiotensin II-infused rats. J Am Soc Nephrol. 1999;10 Suppl 11:S178-S183.

9. Desmouliere A, Geinoz A, Gabbiani F, Gabbiani G. Transforming growth factor-beta 1 induces alpha-smooth muscle actin expression in granulation tissue myofibroblasts and in quiescent and growing cultured fibroblasts. J Cell Biol. 1993;122:103-111.
10. Wolf G. Link between angiotensin II and TGF-beta in the kidney. Miner Electrolyte Metab. 1998;24:174-180.

11. Ruiz-Ortega M, Esteban V, Ruperez M, et al. Renal and vascular hypertension-induced inflammation: role of angiotensin II. Curr Opin Nephrol Hypertens. 2006;15:159-166.

12. Bardin T. Fenofibrate and losartan. Ann Rheum Dis. 2003;62: 497-498.

13. Liberopoulos E, Christides D, Elisaf M. Comparative effects of losartan and irbesartan on serum uric acid in hypertensive patients with hyperuricemia and gout. J Hypertens. 2002;20:347.

14. Wrzner G, Gerster JC, Chiolero A, et al. Comparative effects of losartan and irbesartan on serum uric acid in hypertensive patients with hyperuricaemia and gout. J Hypertens. 2001;19:1855-1860.

15. Manolis AJ, Grossman E, Jelakovic B, et al. Effects of Losartan and candesartan monotherapy and losartan/hydrochlorothiazide combination therapy in patients with mild to moderate hypertension. losartan trial investigators. Clin Ther. 2000;22:1186-1203.

16. Elliott WJ, Calhoun DA, DeLucca PT, Gazdick LP, Kerns DE, Zeldin RK. Losartan versus valsartan in the treatment of patients with mild to moderate essential hypertension: data from a multicenter, randomized, double-blind, 12-week trial. Clin Ther. 2001;23:1166-1179.

17. De Rosa ML, Cardace P, Rossi M, Baiano A, de Cristofaro A. Comparative effects of chronic ACE inhibition and AT1 receptor blocked losartan on cardiac hypertrophy and renal function in hypertensive patients. J Hum Hypertens. 2002;16:133-140.

18. Sica D, Schoolwerth A. Part 1. uric acid and losartan. Curr Opin Nephrol Hypertens. 2002;11:475-482.

19. Kamper AL, Nielsen AH. Uricosuric effect of losartan in patients with renal transplants. Transplantation. 2001;72:671-674.

20. Zhu X, Chen J, Han F, et al. Efficacy and safety of losartan in treatment of hyperuricemia and posttransplantation erythrocytosis: results of a prospective, open, randomized, case-control study. Transplant Proc. 2009;41:3736-3742.

21. Chłopicki S, Koda M, Chabielska E, Buczko W, Gryglewski RJ. Antiplatelet action of losartan involves TXA2 receptor antagonism but not TXA2 synthase inhibition. Journal of Physiology and Pharmacology. 2000;51:715-722.

22. Li P, Ferrario CM, Brosnihan KB. Losartan inhibits thromboxane A2-induced platelet aggregation and vascular constriction in spontaneously hypertensive rats. J Cardiovasc Pharmacol. 1998;32:198-205.

23. Jimnez AM, Montn M, Garca R, et al. Inhibition of platelet activation in stroke-prone spontaneously hypertensive rats: comparison of losartan, candesartan, and valsartan. J Cardiovasc Pharmacol. 2001;37: 406-412.

24. Guerra-Cuesta JI, Montn M, Rodrguez-Feo JA, et al. Effect of losartan on human platelet activation. J Hypertens. 1999; 17:447-452.

25. Montn M, Jimnez A, Nez A, et al. Comparative effects of angiotensin II AT-1-type receptor antagonists in vitro on human platelet activation. J Cardiovasc Pharmacol. 2000;35:906-913.

26. Nez A, Gmez J, Zalba LR, et al. Losartan inhibits in vitro platelet activation: comparison with candesartan and valsartan. Journal of the Renin-Angiotensin-Aldosterone System . 2000;1:175-179.

27. Sato Y, Fujii S, Imagawa S, et al. Platelet aggregability in patients with hypertension treated with angiotensin II type 1 receptor blockers. J Atheroscler Thromb. 2007;14:31-35.

28. Laverman G, Andersen S, Rossing P, Navis G, de Zeeuw D, Parving H. Renoprotection with and without blood pressure reduction. Kidney Int. 2005:S54-S59.

29. Dilek K, Usta M, Ersoy A, et al. Long-term effects of losartan on proteinuria and renal function in patients with renal amyloidosis. Scand $J$ Urol Nephrol. 2002;36:443-446.

30. Iino $\mathrm{Y}$, Hayashi M, Kawamura T, et al. Interim evidence of the renoprotective effect of the angiotensin II receptor antagonist losartan versus the calcium channel blocker amlodipine in patients with chronic kidney disease and hypertension: a report of the japanese losartan therapy intended for global renal protection in hypertensive patients (JLIGHT) study. Clin Exp Nephrol. 2003;7:221-230. 
31. Usta M, Ersoy A, Dilek K, et al. Efficacy of losartan in patients with primary focal segmental glomerulosclerosis resistant to immunosuppressive treatment. J Intern Med. 2003;253:329-324.

32. Tikkanen I, Omvik P, Jensen HA. Comparison of the angiotensin II antagonist losartan with the angiotensin converting enzyme inhibitor enalapril in patients with essential hypertension. J Hypertens. 1995;13: 1343-1351.

33. Chan JC, Critchley JA, Lappe JT, et al. Randomised, double-blind, parallel study of the anti-hypertensive efficacy and safety of losartan potassium compared with felodipine ER in elderly patients with mild to moderate hypertension. J Hum Hypertens. 1995;9:765-771.

34. Hou F, Xie D, Zhang X, et al. Renoprotection of optimal antiproteinuric doses (ROAD) study: a randomized controlled study of benazepril and losartan in chronic renal insufficiency. $J$ Am Soc Nephrol. 2007;18: 1889-1898.

35. Brenner BM, Cooper ME, de Zeeuw D, et al. Effects of losartan on renal and cardiovascular outcomes in patients with type 2 diabetes and nephropathy. New Eng J Med. 2001;345:861-869.

36. Zhang Z, Shahinfar S, Keane W, et al. Importance of baseline distribution of proteinuria in renal outcomes trials: lessons from the reduction of endpoints in NIDDM with the angiotensin II antagonist losartan (RENAAL) study. J Am Soc Nephrol. 2005;16:1775-1780.

37. Bakris G, Weir M, Shanifar S, et al. Effects of blood pressure level on progression of diabetic nephropathy: Results from the RENAAL study. Arch Intern Med. 2003;163:1555-1565.

38. de Zeeuw D, Remuzzi G, Parving H, et al. Proteinuria, a target for renoprotection in patients with type 2 diabetic nephropathy: lessons from RENAAL. Kidney Int. 2004;65:2309-2320.

39. Cetinkaya R, Odabas AR, Selcuk Y. Anti-proteinuric effects of combination therapy with enalapril and losartan in patients with nephropathy due to type 2 diabetes. Int J Clin Pract. 2004;58:432-435.

40. Russo D, Minutolo R, Pisani A, et al. Coadministration of losartan and enalapril exerts additive antiproteinuric effect in IgA nephropathy. $\mathrm{Am}$ J Kidney Dis. 2001;38:18-25.

41. Nakao N, Yoshimura A, Morita H, Takada M, Kayano T, Ideura T. Retraction. Combination treatment of angiotensin-II receptor blocker and angiotensin-converting-enzyme inhibitor in non-diabetic renal disease (COOPERATE): A randomised controlled trial. Ann Intern Med. 2009;151:897.

42. Parving H, Persson F, Lewis J, Lewis E, Hollenberg N. Aliskiren combined with losartan in type 2 diabetes and nephropathy. New Eng J Med. 2008;358:2433-2436.

43. Pitt B, Segal R, Martinez FA, et al. Randomised trial of losartan versus captopril in patients over 65 with heart failure (evaluation of losartan in the elderly study, ELITE). Lancet. 1997;349:747-752.

44. Pitt B, Poole-Wilson PA, Segal R, et al. Effect of losartan compared with captopril on mortality in patients with symptomatic heart failure: randomised trial - the losartan heart failure survival study ELITE II. Lancet. 2000;355:1582-1587.

45. Gottlieb SS, Dickstein K, Fleck E, et al. Hemodynamic and neurohormonal effects of the angiotensin II antagonist losartan in patients with congestive heart failure. Circulation. 1993;88:1602-1609.

46. Konstam M, Neaton J, Dickstein K, et al. Effects of high-dose versus low-dose losartan on clinical outcomes in patients with heart failure (HEAAL study): a randomised, double-blind trial. Lancet. 2009;374: 1840-1848.
47. Dahlf B, Devereux R, Kjeldsen S, et al. Cardiovascular morbidity and mortality in the losartan intervention for endpoint reduction in hypertension study (LIFE): a randomised trial against atenolol. Lancet. 2002;359:995-1003.

48. Devereux RB, Dahlof B, Gerdts E, et al. Regression of hypertensive left ventricular hypertrophy by losartan compared with atenolol: the losartan intervention for endpoint reduction in hypertension (LIFE) trial. Circulation. 2004;110:1456-1462.

49. Okin PM, Devereux RB, Jern S, et al. Regression of electrocardiographic left ventricular hypertrophy by losartan versus atenolol: the losartan intervention for endpoint reduction in hypertension (LIFE) study. Circulation. 2003;108:684-690.

50. Wachtell K, Smith G, Gerdts E, et al. Left ventricular filling patterns in patients with systemic hypertension and left ventricular hypertrophy (the LIFE study). Losartan intervention for endpoint. Am J Cardiol. 2000;85:466-472.

51. Wachtell K, Devereux RB, Lyle PA, Okin PM, Gerdts E. The left atrium, atrial fibrillation, and the risk of stroke in hypertensive patients with left ventricular hypertrophy. Ther Adv Cardiovasc Dis. 2008;2:507-513.

52. Olsen MH, Andersen UB, Wachtell K, Ibsen H, Dige-Petersen H. A possible link between endothelial dysfunction and insulin resistance in hypertension. A LIFE substudy. Losartan intervention for endpointreduction in hypertension. Blood Press. 2000;9:132-139.

53. Olsen MH, Wachtell K, Tuxen C, et al. Opposite effects of losartan and atenolol on natriuretic peptides in patients with hypertension and left ventricular hypertrophy: a LIFE substudy. J Hypertens. 2005;23:1083-1090.

54. Hoieggen A, Alderman MH, Kjeldsen SE, et al. The impact of serum uric acid on cardiovascular outcomes in the LIFE study. Kidney Int. 2004;65:1041-1049.

55. Olsen MH, Fossum E, Hoieggen A, et al. Long-term treatment with losartan versus atenolol improves insulin sensitivity in hypertension: ICARUS, a LIFE substudy. J Hypertens. 2005;23:891-898.

56. Olsen MH, Wachtell K, Beevers G, et al. Effects of losartan compared with atenolol on lipids in patients with hypertension and left ventricular hypertrophy: the losartan intervention for endpoint reduction in hypertension study. J Hypertens. 2009;27:567-574.

57. Ibsen $\mathrm{H}$, Wachtell K, Olsen MH, et al. Does albuminuria predict cardiovascular outcome on treatment with losartan versus atenolol in hypertension with left ventricular hypertrophy? A LIFE substudy. J Hypertens. 2004;22:1805-1811.

58. Okin P, Wachtell K, Kjeldsen S, et al. Incidence of atrial fibrillation in relation to changing heart rate over time in hypertensive patients: the LIFE study. Circ Arrhythm Electrophysiol. 2008;1:337-343.

59. Lindholm LH, Ibsen H, Borch-Johnsen K, et al. Risk of new-onset diabetes in the losartan intervention for endpoint reduction in hypertension study. J Hypertens. 2002;20:1879-1886.

60. Ravera M, Re M, Vettoretti S. Economic evaluation of angiotensin receptor blockers in type 2 diabetes, hypertension, and nephropathy. J Am Soc Nephrol. 2006;17 (4 Suppl 2):S44-S48.

61. Arredondo A, Burke T, Carides G, Lemus E, Querol J. The impact of losartan on the lifetime incidence of ESRD and costs in mexico. Rev Invest Clín. 2005;57:399-405.

62. Boersma C, Voors A, Visser ST, de Jong-van den Berg LT, Postma MJ. Cost effectiveness of angiotensin receptor blocker monotherapy in patients with hypertension in the netherlands: a comparative analysis using clinical trial and drug utilization data. Am J Cardiovas Drugs. 2010;10:49-54.

International Journal of Nephrology and Renovascular Disease

\section{Publish your work in this journal}

The International Journal of Nephrology and Renovascular Disease is an international, peer-reviewed open-access journal focusing on the pathophysiology of the kidney and vascular supply. Epidemiology, screening, diagnosis, and treatment interventions are covered as well as basic science, biochemical and immunological studies. The journal welcomes

\section{Dovepress}

original research, clinical studies, reviews \& evaluations, expert opinion and commentary, case reports and extended reports. The manuscript management system is completely online and includes a very quick and fair peerreview system, which is all easy to use. Visit http://www.dovepress.com/ testimonials.php to read real quotes from published authors. 